\title{
Sensitivities of the absorptive partitioning model of secondary organic aerosol formation to the inclusion of water
}

\author{
M. Barley ${ }^{1}$, D. O. Topping ${ }^{1,2}$, M. E. Jenkin ${ }^{3}$, and G. McFiggans ${ }^{1}$ \\ ${ }^{1}$ Centre for Atmospheric Sciences, School of Earth, Atmospheric \& Environmental Sciences, University of Manchester, \\ Manchester, M13 9PL, UK \\ ${ }^{2}$ National Centre for Atmospheric Sciences, University of Manchester, Manchester, M13 9PL, UK \\ ${ }^{3}$ Atmospheric Chemistry Services, Yelverton, Devon, PL20 6EN, UK
}

Received: 7 October 2008 - Published in Atmos. Chem. Phys. Discuss.: 4 December 2008

Revised: 29 April 2009 - Accepted: 29 April 2009 - Published: 5 May 2009

\begin{abstract}
The predicted distribution of semi-volatile organic components between the gaseous and condensed phase as a function of ambient relative humidity and the specific form of the partitioning model used has been investigated. A mole fraction based model, modified so as not to use molar mass in the calculation, was found to predict identical RH dependence of component partitioning to that predicted by the conventional mass-based partitioning model which uses a molar mass averaged according to the number of moles in the condensed phase. A recently reported third version of the partitioning model using individual component molar masses was shown to give significantly different results to the other two models. Further sensitivities to an assumed pre-existing particulate loading and to parameterised organic component non-ideality are explored and shown to contribute significantly to the variation in predicted secondary organic particulate loading.
\end{abstract}

\section{Introduction}

Aerosol particles may contribute significantly to radiative forcing in the atmosphere by the direct, semi-direct and indirect effects (Solomon et al., 2007); their size and composition determining each of the radiative properties to varying degrees. The aerosol forcings are intrinsically linked to aerosol behaviour in the moist atmosphere - a property that is directly influenced by both inorganic and organic components (Kanakidou et al., 2005). Dependent on conditions, there

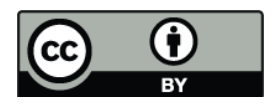

Correspondence to: G. McFiggans (g.mcfiggans@manchester.ac.uk) are a number of possible means by which water vapour may interact with the ambient aerosol. Ambient relative humidity will directly determine the equilibrium water content and size of aerosol particles in the sub-saturated moist atmosphere. This hygroscopicity has been widely investigated and atmospheric measurements reviewed in Swietlicki et al. (2008). As particles encounter supersaturation, cloud droplets may nucleate and grow on those which are able to behave as cloud condensation nuclei under the prevailing conditions. Properties affecting such aerosol "activation" have been summarised in McFiggans et al. (2006). Similarly, nucleation of ice crystals on aerosol particles behaving as ice nuclei, or freezing of aerosol that had previously activated into liquid droplets may occur when exposing an air parcel to the appropriate temperature regime and associated supersaturation with respect to ice. Such behaviour has been reviewed by Cantrell and Heymsfield (2005).

A fourth means by which water may influence the impact of aerosol particles is by directly affecting particulate loading. Many of the components that comprise the majority of the atmospheric aerosol mass are water soluble. Historically, most aerosol mass was considered to be inorganic, dominated by readily soluble electrolyte species. If such components have a gaseous origin ("secondary" components), they will partition to deliquesced aqueous aerosol particles by accommodation at the surface and dissolution into the available water according to their effective solubility. With increasing relative humidity, there will be more water available in the particles and there will be a proportionate increase in the semi-volatile inorganic components dissolved in the available water at equilibrium. This ignores any potential limitation in the kinetics of uptake of the semi-volatile component.

Published by Copernicus Publications on behalf of the European Geosciences Union. 
In recent years, it has become apparent that the atmospheric aerosol comprises significant amounts of organic material. The fractional abundance of organic aerosol (OA) components in submicron particles varies between $20 \%$ to $50 \%$ by mass (Zhang et al., 2005). and comprises thousands of compounds of varying reactivity and molecular structure (Gray et al., 1986; Middlebrook et al., 1998). A significant proportion of these components may be semi-volatile and contribute to the mass of so-called secondary organic aerosol (SOA). There have been many thousands of organic compounds detected in the atmosphere and both anthropogenic "A-" and biogenic "B-" volatile organic compounds (VOCs) are subject to atmospheric oxidation producing a range of VOC oxidation products of widely varying volatilities, determining whether they contribute to SOA formation and growth. The organic aerosol fraction contains a mixture of compounds with a wide range of solubilities in water and it has been estimated that the fraction of the organic carbon in the condensed phase which is water soluble varies between $20 \%$ and $70 \%$ (Saxena and Hildemann, 1997), though the actual water solubility varies widely and is almost invariably lower than that of inorganic components.

In order to predict the amount of secondary organic aerosol, a widely used approach has been to consider the partitioning of semi-volatile organic components in a manner analogous to that described for semi-volatile inorganic water soluble components above. However, instead of dissolution of components in a single dominant solvent, the absorptive partitioning model for organic material has most frequently been used to consider absorption of semi-volatile organic components into an organic medium sufficiently similar in nature for the system to act as a single phase organic solution. This is not a requirement for the absorptive partitioning model and separate phases have been considered in a number of studies, see below. The current study examines the sensitivity of the absorptive partitioning model to a particular aspect of this assumption of similarity to thereby consider the potential influence of water on the partitioning. Whereas other studies have extensively examined details of the non-ideality in the participation of water in absorptive partitioning (e.g., Chang and Pankow, 2008; Pankow and Chang, 2008); even to the extent that phase separation into polar and non-polar phases has been considered (e.g., Erdakos and Pankow, 2004; Erdakos et al., 2006; Chang and Pankow, 2008), this study largely explores the impact of the molar mass and extremely large atmospheric abundance of water vapour on its role in partitioning. A companion paper expands the current approach to consider non-ideality. In addition, a slight modification to the model formulation to conveniently incorporate the volatility basis set approach has been effected.

\section{Absorptive partitioning model formulations}

The partitioning of semi-volatile organic components was originally thought to be dominated by adsorption (Pankow, 1987). Soderholm (1988) discussed particle/vapour interactions and derived an expression for the mass concentration of the saturated vapour. Pankow (1994) developed an equilibrium partitioning model in an attempt to distinguish between absorptive partitioning into a condensed phase and adsorption onto the particle surface. Pankow et al. (2001) developed the absorptive partitioning model to describe the gas/particle partitioning of each component in a complex multicomponent system. The condensation of multiple organic compounds into an aerosol needs to take account of interactions between molecules in the condensed phase (deviations from Raoult's Law) as well as the volatility of the components. The absorptive partitioning model provides a mathematically simple method of predicting the condensed phase composition in a multicomponent system at temperatures and pressures relevant to the atmosphere. Donahue et al. (2006) further developed the model to consider a number of condensable compounds with a broad range of volatility. This approach allows use of large numbers of potentially condensable compounds by binning them according to their saturation concentration $C_{i}^{*}$ value. The amount of condensed material is calculated by summing all components $i$ ensuring mass balance between the two phases for each component considered. Defining a partitioning coefficient $\xi_{i}$ for compound $i$ given its $C_{i}^{*}$ value:

$\xi_{i}=\left(1+\frac{C_{i}^{*}}{C_{O A}}\right)^{-1}$

the total mass of condensed organic material, $C_{O A}$, is given by the sum of the products of the individual total component concentrations in both phases and their partitioning coefficient:

$C_{O A}=\sum_{i} C_{i} \xi_{i}$

The partitioning predictions of Donahue et al. (2006) and Pankow (1994) are defined by two closely related expressions, Eqs. 3 and 4 respectively):

$$
\begin{aligned}
& C_{i}^{*}=\frac{C_{i}^{\text {vap }} C_{O A}}{C_{i}^{\text {cond }}}=\frac{10^{6} M_{i} \gamma_{i} P_{i}^{0}}{R T} \\
& K_{p, i}=\frac{R T}{10^{6} M_{o m} \gamma_{i} P_{i}^{0}}
\end{aligned}
$$

where

$C_{i}^{\text {vap }}$ is the vapour phase concentration of component $i$, $\mu \mathrm{gm}^{-3}$,

$C_{i}^{\text {cond }}$ is the condensed phase concentration of component $i$, $\mu^{-3} \mathrm{gm}^{-3}$,

$C_{i}=C_{i}^{\text {vap }}+C_{i}^{\text {cond }}$ is the total loading of component $i, \mu \mathrm{gm}^{-3}$, 
$P_{i}^{0}$ is the saturated vapour pressure of component $i$, atm,

$R$ is the ideal gas constant $=8.2057 \times 10^{-5}$ $\mathrm{m}^{3}$ atm $\mathrm{mol}^{-1} \mathrm{~K}^{-1}$,

$T$ is the temperature, $\mathrm{K}(=298.15 \mathrm{~K}$ for this work),

$\gamma_{i}$ is the activity coefficient for component $i$ in the liquid phase and

$C_{i}^{*}$ is the effective saturation concentration, $\mu \mathrm{gm}^{-3}$. In both cases $C_{i}^{*}$ (or the inverse of $K_{p, i}$ ) will have units of $\mu \mathrm{gm}^{-3}$. In comparing these formulations it is important to note that $C_{i}^{*}$ (Eq. 3) is not the reciprocal of $K_{p, i}$ (Eq. 4) as $M_{i}$ is not the same as $M_{o m}$ (see below). Calculation of the partitioning in both models can be seen to require vapour pressure data for the condensable species $P_{i}^{0}$ and information on the non-ideality (deviations from Raoult's Law) of the condensed components.

$M_{o m}$ is the molar mass averaged according to the number of moles in the condensed material (SOA and water) given by Eq. (5) below in which all concentrations in this case $\left(C_{O A}\right.$ and $C_{i}$ ) are in molar units (specifically $\mu \mathrm{mol} \mathrm{m}^{-3}$ ),

$M_{o m}=\frac{\sum_{i} C_{i} \xi_{i} M_{i}}{\sum_{i} C_{i} \xi_{i}}=\frac{\sum_{i} C_{i} \xi_{i} M_{i}}{C_{O A}}$

In Donahue et al. (2006), the molecular weight term was redefined as that of the condensing species $\left(M_{i}\right.$ in Eqs. 3 and 5.). One way that the equilibrium coefficient $\left(K_{p, i}\right)$, as defined in Eq. (4), can be made to equal the reciprocal of the mass concentration of the saturated vapour $\left(C_{i}^{*}\right)$, as defined in Eq. (3), is through use of a modified activity coefficient, $\gamma_{i}$ accounting for the redefinition of $M_{i}$ as outlined in the supplementary material to Donahue et al. (2006). In order for the two formulations to be equivalent without redefinition and recalculation of activity coefficients, it is implied that the difference in molecular weights between different components was not significant. This may be a reasonable assumption when considering the condensation of similar hydrocarbon species as emitted from vehicle exhausts; but is likely to make a difference if one of the components has a significantly different molecular weight to the others. The magnitude of the required redefinition and recalculation of the activity coefficients is examined in the results section.

Seinfeld et al. (2001) obtained an expression explicitly accounting for the effects of relative humidity on partitioning of organic material. By taking derivatives of $K_{p}$ at constant $T$ and $p$ and straightforward manipulation of Eq. (4), the following expression was derived as their Eq. (17):

$\frac{d K_{p, i}}{d \mathrm{RH}}=-K_{p, i} \frac{d \ln M W_{o m}}{d \mathrm{RH}}-K_{p, i} \frac{d \ln \gamma_{i}}{d \mathrm{RH}}$

where $M W_{o m}$ is a number averaged molar mass identical to $M_{o m}$ in Eq. (4). The first term denotes the RH-dependence of $K_{p, i}$ resulting from changes in $M W_{o m}$ and the second term, that resulting from changes in $\gamma_{i}$. By inspection of
Eqs. (4) and (6), since water has a very low $M W$ it will always tend to increase $K_{p, i}$. The effect of the second term of Eq. (6) is more difficult to predict since the activity coefficient variation with $\mathrm{RH}$ will be more complex and depend largely on the hydrophilic $\left(\frac{d \ln \gamma}{d \mathrm{RH}}<0\right)$ or less hydrophilic $\left(\frac{d \ln \gamma}{d \mathrm{RH}}>0\right)$ nature of the partitioning organic components. This work focuses on the impacts of the first term in Eq. (6) resulting from the molecular weight differences. The second term of Eq. (6) will only briefly be discussed in Sect. 3.3.3.

\subsection{Reformulation of the mass-based partitioning model}

As originally developed, absorptive partitioning has been widely used to model aerosol formation in chamber experiments (Odum et al., 1996, 1997; Kamens et al., 1999; Pankow et al., 2001). The chamber SOA experiments are interpreted as a mass balance between the oxidised mass of hydrocarbon species $\left(\Delta M_{H C}\right)$ and the organic aerosol mass $\left(\triangle M_{O A}\right)$ produced from the $\mathrm{n}$ partitioning semi- (or non)volatile oxidation products $\left(P_{1}, P_{2}, \ldots P_{n}\right)$, so the yield (mass fraction, $F_{O A}$ ) can be expressed as:

$$
\begin{array}{r}
F_{O A}=\frac{\Delta M_{O A}}{\Delta M_{H C}}=C_{O A} \sum_{i} \frac{\alpha_{i} K_{p, i}}{1+C_{O A} K_{p, i}} \\
=\sum_{i} \frac{\alpha_{i}}{1+C_{i}^{*} / C_{O A}}
\end{array}
$$

where $\alpha_{i}$ is the mass-based stoichiometric yield (not stoichiometric coefficients) of compound $i$. Such a mass based approach is convenient in interpreting chamber experiments where aerosol mass may be measured, but molecular information about the condensed mass is lacking. Aiming to predict the formation of SOA from the products of gaseous oxidation Johnson et al. (2005) generated a range of condensable molecules using the Master Chemical Mechanism (MCM), (Jenkin et al., 1997, 2003; Saunders et al., 2003; Bloss et al., 2005), an explicit model of the degradation of atmospheric VOCs. These explicit models provide calculated molecular concentrations of a large number of species potentially contributing to the SOA. This allows the reformulation of the partitioning model in terms of the molar abundance of components. Whilst practical difficulties would be encountered using such an approach to interpret experimental data with measurements of aerosol mass and a generally incomplete speciation of components, theoretical prediction of SOA precursors such as that of Johnson et al. (2005) lend themselves to a molar partitioning consideration. If required, predictions of condensed molar abundance may be simply converted into mass using molecular weights explicit in the detailed component speciation. In the current work, the convenient volatility-binning formalism has been preserved, making the following changes: 
Table 1. Physical properties and $C_{i}^{*}$ Values used in the partition model comparisons.

\begin{tabular}{lcccccr}
\hline Compound & Mol.Wt. & $\begin{array}{c}P^{0} @ 25^{\circ} C \\
\mathrm{~mm} \mathrm{Hg}\end{array}$ & $\begin{array}{c}C_{i}^{*}(\mathrm{mass}) \\
\mu \mathrm{g} \mathrm{m} \mathrm{m}^{-3}\end{array}$ & $\begin{array}{c}C_{i}^{*}(\mathrm{~mole}) \\
\mu \mathrm{mol} \mathrm{m} \mathrm{m}^{-3}\end{array}$ & $\log _{10} C_{i}^{*}(\operatorname{mass})$ & $\log _{10} C_{i}^{*}(\mathrm{~mole})$ \\
\hline Dimethyl ether & 46.069 & 4440 & $1.100 \times 10^{10}$ & $2.388 \times 10^{8}$ & 10.0414 & 8.3780 \\
Acetone & 58.08 & 231.5 & $7.231 \times 10^{8}$ & $1.245 \times 10^{7}$ & 8.8592 & 7.0952 \\
N-pentanol & 88.096 & 2.1975 & $1.041 \times 10^{7}$ & $1.182 \times 10^{5}$ & 7.0175 & 5.0726 \\
Maleic acid & 116.03 & $1.19 \times 10^{-5}$ & $7.426 \times 10^{1}$ & $6.400 \times 10^{-1}$ & 1.8708 & -0.1938 \\
Water & 18.016 & 23.775 & $2.304 \times 10^{7}$ & $1.279 \times 10^{6}$ & 7.3625 & 6.1069 \\
Ethanol & 46.048 & 59.025 & $1.462 \times 10^{8}$ & $3.175 \times 10^{6}$ & 8.1649 & 6.5017 \\
N-decane & 142.176 & 1.58 & $1.209 \times 10^{7}$ & $8.502 \times 10^{4}$ & 7.0823 & 4.9295 \\
\hline
\end{tabular}

(i) removal of the molecular weight term from the expression for $C_{i}^{*}$

$$
C_{i}^{*}=\frac{10^{6} \gamma_{i} P_{i}^{0}}{R T}
$$

where the terms have the same meaning as in Eqs. (1) and (2) and $C_{i}^{*}$ is now the saturation vapour concentration in $\mu \mathrm{mol} \mathrm{m}^{-3}$. This is still used in Eqs. (1) and (2) although now the total concentration of condensed phase organic material $\left(C_{O A}\right)$ is in $\mu \mathrm{mol} \mathrm{m}{ }^{-3}$ rather

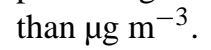

(ii) incorporation of the absorptive partitioning of water in its own volatility bin with physical properties taken from steam tables (see Table 1). The data in the steam tables were derived from a canonical function for the reduced free enthalpy (Gibbs function) with the position of the saturation line defined by a correlation of reduced saturation pressure against reduced temperature (k-function) (Schmidt and Grigull, 1982). The $C_{i}^{*}$ value for water was calculated from its vapour pressure and the system temperature. The abundance of water in the system was calculated from the product of vapour density at the saturation line $\left(23.041 \mathrm{~g} \mathrm{~m}^{-3}\right.$ or $7.7031 \times 10^{17}$ molecule $\mathrm{cm}^{-3}$ at $25^{\circ} \mathrm{C}$ ) and the relative humidity. In principle, any component may be attributed its own volatility value; in practice only water is sufficiently abundant to introduce significant errors were it lumped with other components.

(iii) For those cases where large numbers of compounds are considered it may be appropriate to use the convenient volatility-binning formalism of Donahue et al. (2006) in which a basis set of $C_{i}^{*}$ values separated by factors of 10 in molar units is defined,

$$
C_{\text {bin }}^{*}=\{0.010 .1110100100010000100000\}
$$

Using the $C_{i}^{*}$ value in each logarithmically-spaced bin equal to the geometric mean value of the bin boundaries was found to replicate the results obtained by explicitly incorporating individual compounds less accurately than using a total abundance averaged $C_{\mathrm{bin}}^{*}$ for all components in a single bin

$C_{\mathrm{bin}}^{*}=\frac{\sum_{i} C_{i} C_{i}^{*}}{\sum_{i} C_{i}}$

for all components in a single bin (where all concentrations are in $\mu \mathrm{mol} \mathrm{m} \mathrm{m}^{-3}$ ). This is identical to a condensed abundance averaged value.

(iv) calculation of an abundance averaged molar mass for each bin (using $C_{i}^{*}$ in $\mu \mathrm{mol} \mathrm{m}{ }^{-3}$ ):

$M_{\mathrm{bin}}=\frac{\sum_{i} C_{i} M_{i}}{\sum_{i} C_{i}}$

As all components in a bin partition to the same extent this abundance averaged molar mass is the average molar mass of the condensed material provided by compounds in this bin and is used to convert the number of moles of condensed material in each bin into a corresponding mass after the partitioning calculation.

This reformulation of the partitioning method is readily applicable to the condensation of components with widely varying molar mass. Removing the molar mass term makes the calculation simpler while providing identical results to those from the model using massbased partitioning and averaged molar mass (see below). The partitioning is calculated on a mole basis using the reformulated model. If required, the resulting mass for each component can be obtained by multiplying the number of moles condensed by the appropriate molar mass. 


\section{Results}

Predictions using the molar partitioning model were compared with conventional mass-based approaches for a number of case studies.

\subsection{Partitioning of semi-volatile components of known volatility}

The component physical properties used in the test cases are summarised in Table 1 . They were chosen to provide a wide range of vapour pressures rather than for their atmospheric relevance. However maleic acid may be a significant contributor to SOA under some conditions and the other compounds were selected because they had very different volatilities to maleic acid; and good quality vapour pressure data were available. A wide range of volatilities was needed to highlight the differences between the models. All calculations have been carried out at $25^{\circ} \mathrm{C}$ and vapour pressure data are from the following sources: dimethyl ether, (Florusse et al., 2002); acetone, (Ambrose et al., 1974); n-pentanol and ethanol, (Ambrose et al., 1970); maleic acid, vapour pressure and boiling point estimated by the method of Nannoolal et al. (2004, 2008) with a boiling point correction derived from that required to accurately predict experimental vapour pressure data for succinic acid (structurally very similar to maleic acid) using the same estimation methods; water, (Schmidt and Grigull, 1982); n-decane, (Salerno et al., 1986), interpolated to give a value at $25^{\circ} \mathrm{C}$.

\subsubsection{Comparisons in dry conditions}

The predicted composition of condensed material derived from a mixture of four organic compounds (selected for their wide range of volatilities) was used to compare the three partitioning methods (mass basis using Eq. (3) - "Mass_3", mass basis using Eq. (4) - "Mass_4" and molar basis - "Mol") assuming ideality. This assumption is clearly incorrect, but is used for illustrative purposes. The abundances of the four components were selected such that roughly the same amount of each component was condensed when calculated using the mole based partitioning assuming ideality. It is apparent (from Fig. 1) that the Mass_4 method and the Mol partitioning method were in agreement while the Mass_3 method predicts that a greater amount of the more volatile material condenses and (for the condensation of a similar amount of each compound) the discrepancy increases the more volatile the compound; this is caused by the difference in molar mass between the compounds rather than directly by their increasing volatility.

If the values are recalculated with the same molar mass for all four components then all three models are in agreement and the disagreement demonstrably results from use of the molar mass of the condensing species in the calculation of $C_{i}^{*}$

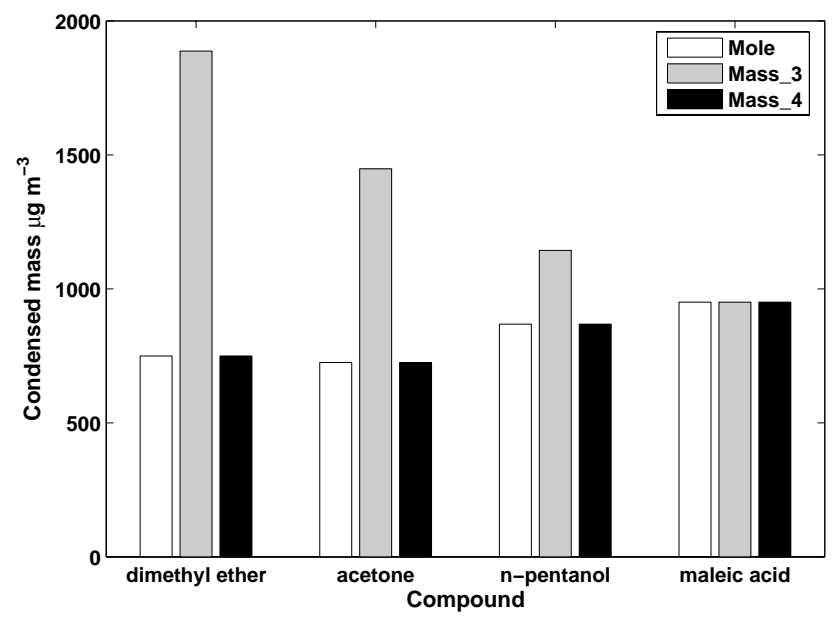

Fig. 1. Predicted condensed mass of each component of a four component organic mixture as predicted by three models. The initial mixture consisted of (in $\mathrm{g} \mathrm{m}^{-3}$ ):- dimethyl ether: 3824; acetone: 192.9; n-pentanol: 2.194; and maleic acid: $9.632 \times 10^{-4}$.

\subsubsection{Partitioning in systems with components more widely differing in molar mass}

The above result may be further extended to consider the two component condensation of decane with either ethanol or water, again assuming ideality for simplicity. Results from a fourth model, the isothermal flash calculation (Raal and Muhlbauer, 1998), may be compared with those from the three models described above. An isothermal flash calculation provides the composition of the liquid and vapour phase in equilibrium at the specified temperature and at either a specified system pressure or a specified ratio of liquid to vapour; for example, a stream of vapour (mole fraction, $i=z_{i}$ ) subjected to an increase in pressure causing partial condensation to form a liquid phase (mole fraction, $x_{i}$ ) in equilibrium with a vapour (mole fraction, $y_{i}$ ). This is directly analogous to the partitioning between the gaseous and liquid components in an atmospheric aerosol. In the flash calculation the following equations are solved iteratively for all components (Raal and Muhlbauer, 1998):

$$
\begin{aligned}
& K_{i}=y_{i} / x_{i} \\
& \sum_{i} x_{i}=\sum_{i} y_{i}=1 \\
& F=V+L \\
& F z_{i}=V y_{i}+L x_{i}
\end{aligned}
$$

Where $F, V$ and $L$ are the total number of moles in the initial stream, the vapour phase and the liquid phase respectively. These equations can be rearranged into an expression which can be solved for the vapour fraction $(=V / F)$. 


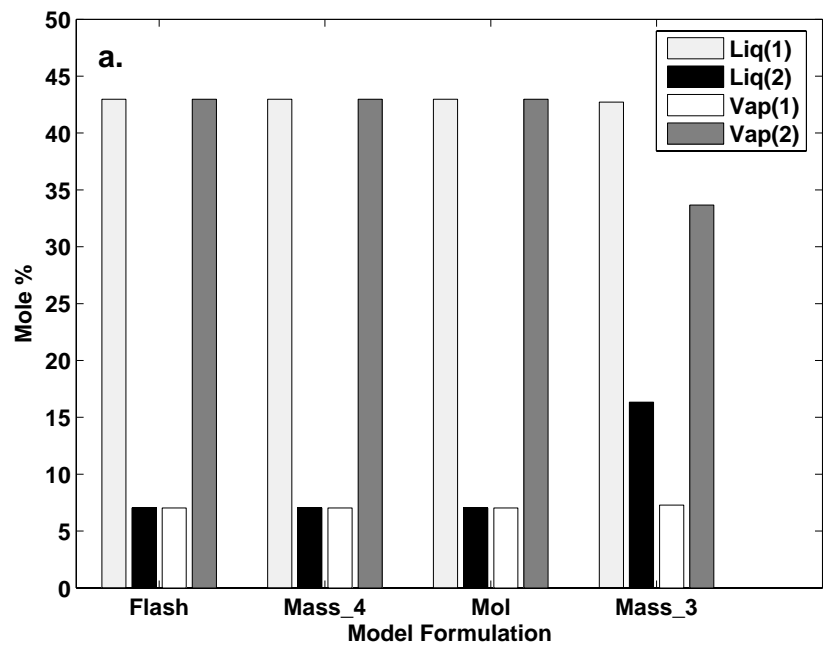

Fig. 2a. Vapour and liquid phase compositions for: (a) ndecane(1)/ethanol(2) as predicted by four models. Note that the phase composition is in mole $\%$.

If the vapour fraction has been specified then $L$ is known $(L=F-V)$ and

$x_{i}=\frac{z_{i}}{\left(\left(\frac{L}{F}\right)+K_{i}\left(\frac{V}{F}\right)\right)}$

and the system pressure is given by: -

$p=\sum_{i} x_{i} p_{i}^{0}$

A flash calculation can be made providing sufficient material is in the stream for condensation to occur; i.e. the pressure, $p$, is between the bubble point and dew point pressures. For the case of an atmospheric aerosol neither the partial pressure of the aerosol nor the liquid fraction is known a priori, so for this work a special case was selected. Setting the abundance of both components to the geometric mean of the $C_{i}^{*}$ value (in $\mu \mathrm{mol} \mathrm{m}{ }^{-3}$ ) gives a total vapour concentration equal to twice the average saturated vapour concentration. This means that half the material will condense to form a liquid and half will remain in the vapour. For the flash calculation, the vapour fraction $(V / F)$ is thus set to 0.5 . Using this abundance in either Mol or Mass_4, confirms that half the available moles condense and the same liquid composition and system pressure are predicted (see Fig. $2 b$ for the decane/ethanol and decane/water binary systems respectively).

With the same inputs, Mass_3 gives a different proportion of each component in each phase. Specifically Mass_3 overpredicts the amount of the most volatile component (i.e. the component with the lowest molecular weight) found in the liquid phase. The isothermal flash calculation with the same inputs and $V / F=0.5$ gave a liquid composition in excellent agreement with $\mathrm{Mol}$ and Mass_4 but quite different from that

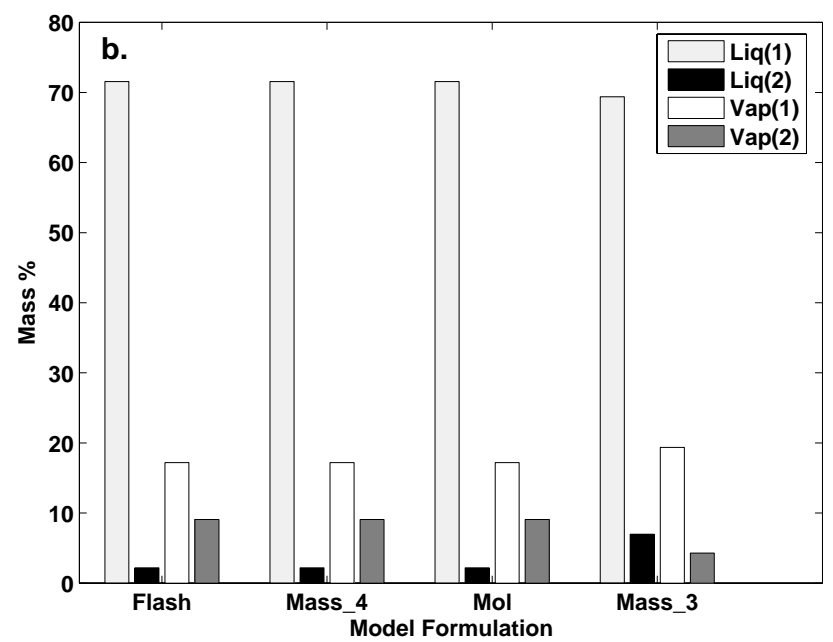

Fig. 2b. Vapour and liquid phase compositions for (b) ndecane(1)/water(2) as predicted by four models. Note that the phase composition is in mass $\%$.

given by Mass_3 (see Fig. 2b). Partitioning model results should be consistent with the isothermal flash calculation; both being derived from the same laws (i.e. Dalton's law of partial pressures, ideal gas law and Raoult's law) and assumptions (all activity coefficients $=1$ ).

\subsection{Predicted impacts of inclusion of water using the volatility basis set approach}

Figure 1a in Donahue et al. (2006) shows an example of typical ambient partitioning with a total condensed organic mass, $C_{O A}$, of $10.64 \mu \mathrm{g} \mathrm{m}^{-3}$. The mass in each of 8 decades of the $\log _{10}\left(C^{*}\right)$ basis set from -2 to +5 is $2.5,1.8,4.0,4.0$, $6.0,5.2 ; 6.2$ and $8.0 \mu \mathrm{g} \mathrm{m}^{-3}$ organic mass respectively (all components having the same molar mass of $250 \mathrm{~g} \mathrm{~mol}^{-1}$ ), as shown in Fig. 3b. The inclusion of water at a concentration equivalent to $80 \% \mathrm{RH}\left(18.43 \mathrm{~g} \mathrm{~m}^{-3}\right.$ based on a saturated vapour density for water Schmidt and Grigull, 1982) leads to a total mass prediction of $74.22 \mu \mathrm{g} \mathrm{m}^{-3}$ of which $14.74 \mu \mathrm{g} \mathrm{m}^{-3}$ was organic material partitioned as shown in Fig. 3b.

It can be seen that components in bins 0 to 3 are most responsible for the difference in condensed organic mass. Hence the inclusion of water in the calculation predictably increases both the organic and total condensed mass. Increasing the RH with the same organic distribution leads to a prediction of increasing condensed organic mass in all three models. The loadings are the same if all the components in all the bins are given the same molecular weight. If, however, a realistic range of molecular weights is assigned to these bins (for example the least volatile bin $(-2)$ was assigned a molar mass of $300 \mathrm{~g} \mathrm{~mol}^{-1}$, the next bin (-1) 250 and soon in steps of 50 up to bin +1 at 150 and then continuing 


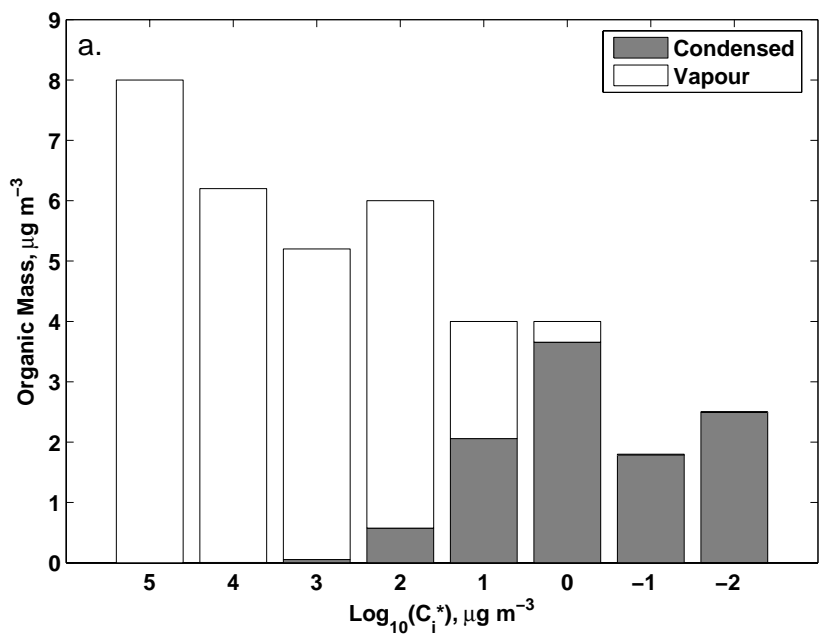

Fig. 3a. The effect of ambient $\mathrm{RH}$ on the partitioning prediction using Mass_3 model and assumed ideality with the same total organic loading in both panels (all organic components have been assigned a molar mass of $250 \mathrm{gmol}^{-1}$ ): (a) dry air, total condensed mass $=$ organic condensed mass $=10.64{\mu \mathrm{gm}^{-3}}^{-3}$.

in steps of 25 so that the most volatile bin $(+5)$ is assigned a molar mass of $50 \mathrm{~g} \mathrm{~mol}^{-1}$; see caption to Fig. 4) then the results differ. The Mass_4 and Mol models predict identical amounts of condensed organic and total mass, while the Mass_3 model predicts slightly higher organic mass and a much greater increase in condensed water with increasing RH (Fig. 4). The discrepancy between the predictions for SOA made by the Mass_3 and either of the Mass_4 or Mol models in this example is small and it is sensitive to the molar mass distribution assigned to the bins. For example if all organic components have the same molar mass then this discrepancy disappears; if the molar mass of each bin is doubled (so that the distribution across the range of bins varies from 600 to 100) then the discrepancy between the models remains the same $\left(0.76 \mu \mathrm{g} \mathrm{m}^{-3}\right)$; however if the molar mass distribution above is used but with each value increased by 50 then the discrepancy is reduced (to $0.746 \mu \mathrm{g} \mathrm{m}^{-3}$ ); while if each molar mass value is decreased by 30 from the above distribution then the discrepancy increases (to $1.127 \mu \mathrm{g} \mathrm{m}^{-3}$ ). These calculations demonstrate that it is the ratio of the molar mass of the organic components that determine the difference in predicted SOA between the models.

It should be re-emphasised that this change in predicted total material solely results from changes in the partitioning coefficient resulting from the reducing average molecular mass of condensing species with increasing RH, but not changes resulting from variation in component activity coefficient with changing condensed water content, i.e. the first, but not the second, term in Eq. (17) in Seinfeld et al. (2001). The condensed water is treated as an absorbing phase in the same way as the condensed organic components and this is

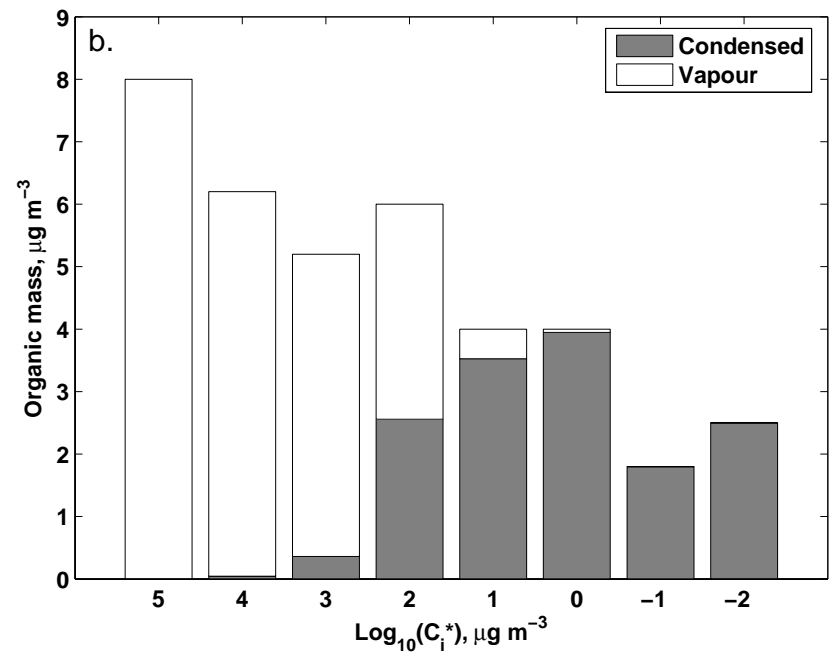

Fig. 3b. Same as panel (a) but for moist air ( $\mathrm{RH}=80 \%)$, total condensed mass $=74.22 \mu \mathrm{gm}^{-3}$, of which organic condensed mass $=14.74{\mu \mathrm{gm}^{-3}}^{-}$.

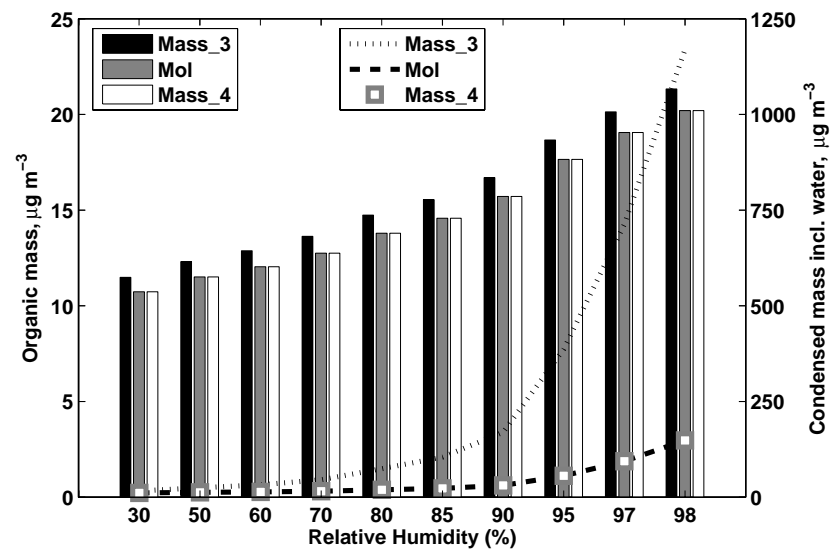

Fig. 4. The partitioning of the organic components shown in Fig. 3 as a function of RH as predicted by three models assuming ideality. The $\log _{10}\left(C_{i}^{*}\right)$ bins have been given the following molecular weight distribution (in $\mathrm{g} \mathrm{mol}^{-1}$ ), $-2,300 ;-1,250 ; 0,200 ;+1,150 ;+2$, $125 ;+3,100 ;+4,75 ;+5,50$. The chart shows the total condensed organic mass on the left axis and total condensed mass including water on the right axis.

reflected in an increase in the total condensed mass. The second term in Eq. (17) of Seinfeld et al. (2001) may lead to a significant reduction in the influence of water on partitioning, but the first term cannot a priori be excluded.

A comparison of the predicted abundance of water as a function of RH is shown in Fig. 5b in terms of mole and mass fraction. It is clear that the Mol and the Mass_4 models both predict an abundance of water consistent with Raoult's Law, whilst the Mass_3 model predicts a mass fraction of water 
a.

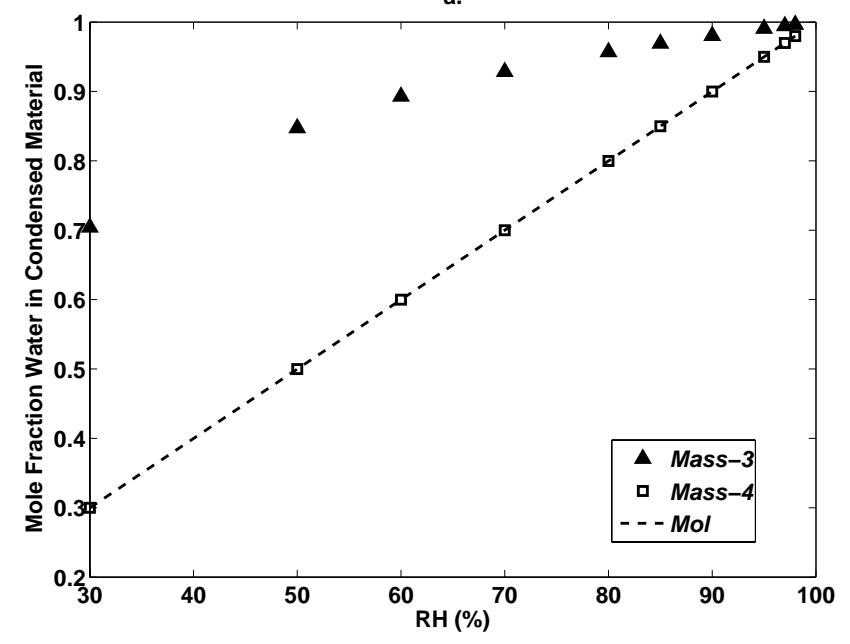

Fig. 5a. The composition of the condensed material by each model as a function of $\mathrm{RH}$ : mole fraction.

equal to the RH (indeed, for all semi-volatile compounds, the Mass_ 3 model will predict a mass rather than mole fraction equal to its gaseous saturation ratio). This illustrates the magnitude of the correction required in the modified activity coefficients, $\gamma_{i}$, to account for both scale change and non-ideality in the Mass 33 model to comply with the conventional definition of Raoult's Law in terms of component mole fraction (and non-ideal deviation).

\subsection{Further partitioning sensitivities to RH using the molar partitioning model}

\subsubsection{Condensed mass variation with total abundance of the most volatile condensing component and its molecular weight}

Given that all formulations of the partitioning exhibit sensitivity to component molecular weight variation in general and to the availability of atmospheric water as a low molecular weight semi-volatile component in particular, the behaviour of the model with abundance of the lowest volatility (and molecular weight) component was investigated. First, consider the effect of variation of total abundance of semivolatile components $A, B$ and $C$ on predicted aerosol mass. Figure 6 shows a case where $C_{A}^{*}>C_{B}^{*}>C_{C}^{*}$ ( $A$ is more volatile than $B$ which is more volatile than $C$ ) and their abundances follow the same trend such that each makes a significant contribution to the condensed aerosol. Assuming an activity coefficient of unity for all components and the same molecular mass $\left(250 \mathrm{~g} \mathrm{~mol}^{-1}\right)$, the predicted condensed mass of the least volatile compounds $(B+C)$ is almost two orders of magnitude greater at 0.95 saturation ratio of $A$ than when $A$ is absent at low $B+C$ total loading, less than a factor of three greater at intermediate $B+C$ loading

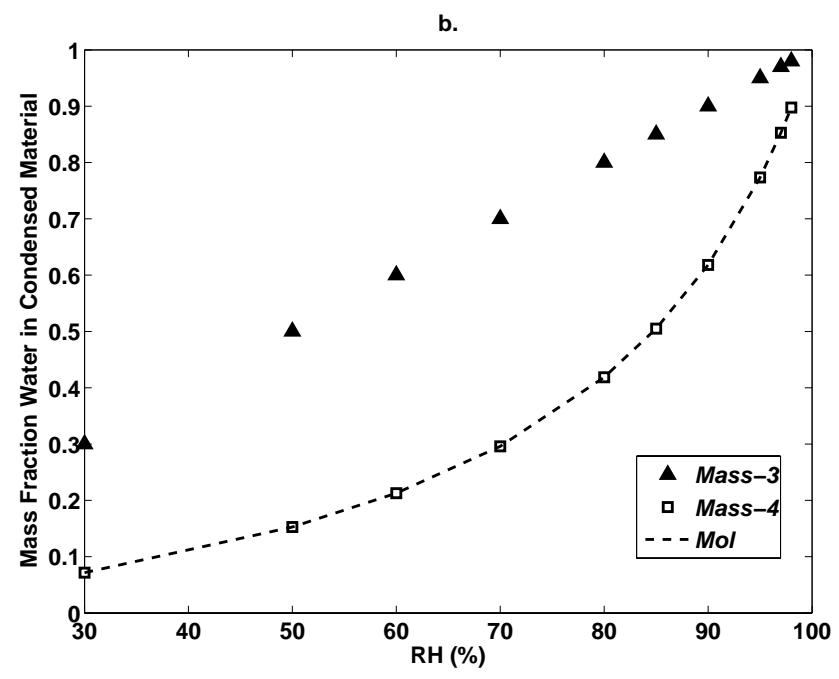

Fig. 5b. The composition of the condensed material by each model as a function of $\mathrm{RH}$ and mass fraction.

and less than $20 \%$ greater at high $B+C$ loading. The additional condensed mass of $A$ with the increasing saturation ratio of $A$ is similar at all total concentrations of $B+C$.

This prediction is obviously independent of the formulation of the model chosen, since the molecular masses are identical. Repeating the calculation, assuming that component $A$ is water (and that it is appropriate to consider water as participant in absorptive partitioning), i) the RH dependence of the condensed organic mass and ii) the variability in $\mathrm{RH}$ dependence of condensed organic mass with total organic abundance are both again evident. Using the Mol model a discrete volatility bin for water with a $\log _{10}\left(C_{w}^{*}\right)$ value on a molar basis at $25^{\circ} \mathrm{C}$ of 6.1067 , the $\mathrm{RH}$ dependence of the particulate mass comprising organic components $B$ and $C$ and particulate water is shown in Fig. 7).

$B$ and $C$ have molar-based $C_{i}^{*}$ values of 0.4 and $0.004 \mu \mathrm{mol} \mathrm{m}{ }^{-3}$ respectively. If the molar masses of $B$ and $C$ are both $250 \mathrm{~g} \mathrm{~mol}^{-1}$, this is equivalent to mass-based $C_{B}^{*}$ and $C_{C}^{*}$ values of 100 and $1 \mu \mathrm{g} \mathrm{m}^{-3}\left(\log _{10}\left(C_{i}^{*}\right)\right.$ mass based bins 2 and 0 ). Three cases were investigated with increasing total organic abundances of $0.008,0.08,0.8 \mu \mathrm{mol} \mathrm{m}{ }^{-3}$ (2, 20 and $\left.200 \mu \mathrm{g} \mathrm{m}^{-3}\right)$ of component $B$ and $0.004,0.04$, $0.4 \mu \mathrm{molm}^{-3}\left(1,10\right.$ and $\left.100 \mu \mathrm{gm}^{-3}\right)$ of component $C$. From Fig. 7 it can be seen that, between RH of 0 and $95 \%$ the predicted dependence of the mass of both total organic $(B+C)$ and of organic plus water is significant. Figure 7 shows the change in RH dependence for three different values of the total abundances of the two organic components $(B+C)$. As in the previous case, the dependence on the saturation ratio (in this case RH) of the most volatile component with concentration of the condensed organic mass of components $B+C$ is large. The great decrease in RH sensitivity with increased total loading of $B+C$ can be seen. It can be seen from Fig. 7 


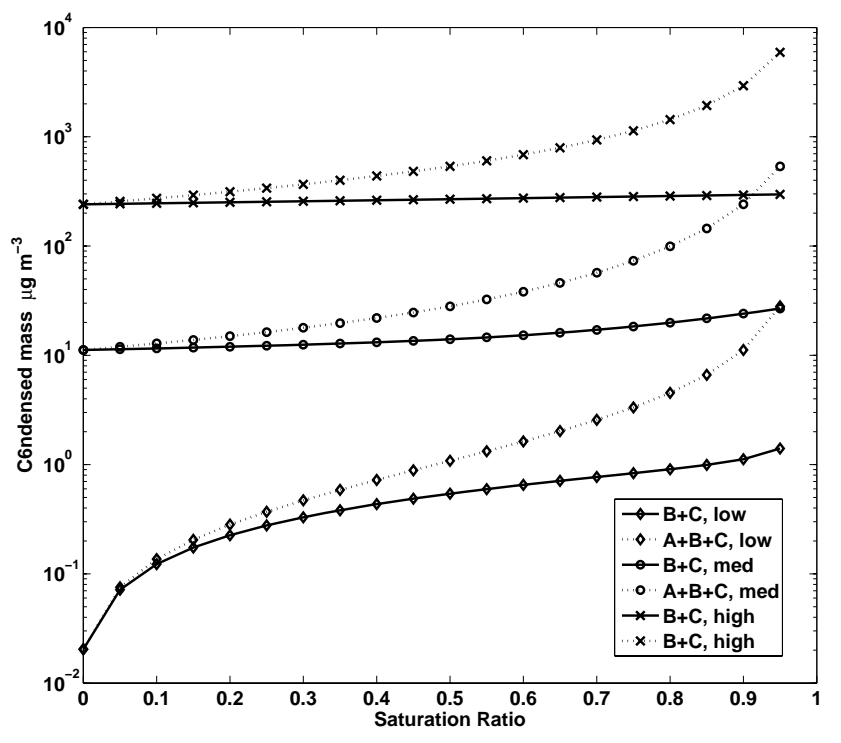

Fig. 6. Aerosol mass variation with component $A$ concentration using the molar partitioning model.

that there is a lower additional mass of condensed water at 95\% RH compared with dry conditions than the additional mass of component $A$ in Fig. 6. This is because of the lower molar mass of water compared with component $A$. The additional number of moles of component $A$ in Fig. 6 and of water in Fig. 7 is the same with changing saturation ratio (or $\mathrm{RH})$. Figure 7 shows the change in RH dependence for three different values of the total abundances of the two organic components $(B+C)$. It is evident from the much stronger dependence of condensed organic mass on $\mathrm{RH}$ at low organic molecular abundance $\left(2 \mu \mathrm{g} \mathrm{m}^{-3} B\right.$ and $\left.1 \mu \mathrm{g} \mathrm{m}^{-3} C\right)$ than at high abundance $\left(200 \mu \mathrm{g} \mathrm{m}^{-3} B\right.$ and $\left.100 \mu \mathrm{g} \mathrm{m}^{-3} C\right)$, that the precursor concentration at which SOA formation experiments are conducted will influence the observed $\mathrm{RH}$ dependence. This is solely the result of keeping the total water abundance within the range of atmospheric concentrations whilst varying the total OA concentrations by orders of magnitude. It is readily expected that total wet mass will be dependent on $\mathrm{RH}$, but it can be clearly seen that total dry organic mass will also be dependent on RH and that the dependence of total partitioning mass (dry or wet) will depend on total abundance of organic material.

Furthermore, as has previously been reported, the contribution of the more volatile organic component to the organic aerosol mass is predicted to be significantly greater at high concentrations (and higher RH).

\subsubsection{Dependence of condensed organic mass loading prediction on pre-existing core}

Figure 8 shows the predicted dependence of the condensed mass on the availability of a fully-miscible but involatile

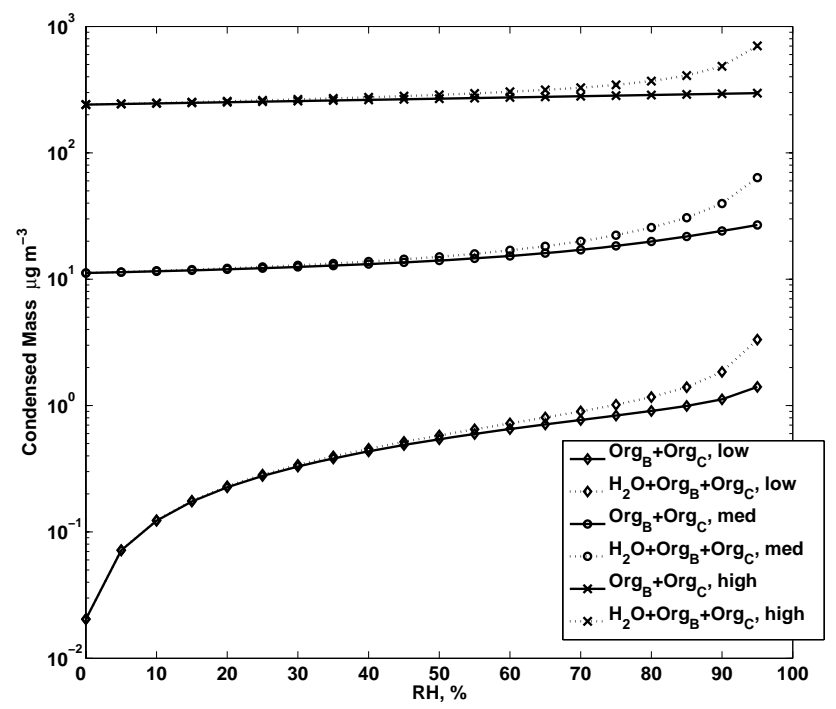

Fig. 7. Aerosol mass variation with relative humidity using the molar partitioning model.

core, behaving ideally. It can be seen that, at constant RH, the condensed semi-volatile organic mass increases with core mass as would be expected from the above discussion. However as the total absorptive mass still increases with RH due to the increased liquid water content; so the amount of condensed semi-volatile organic material still increases with RH. It can be seen that there is a very marginal increase in sensitivity to RH at lower core mass. The molar mass of the core material was set in all cases to $250 \mathrm{~g} \mathrm{~mol}^{-1}$. Since the predicted condensed mass depends only on the available number of moles, increasing the molar mass to e.g. 500 or $2500 \mathrm{~g} \mathrm{~mol}^{-1}$ has the same effect as reducing the core mass to 0.5 or $0.1 \mu \mathrm{g} \mathrm{m}^{-3}$ respectively, maintaining the molar mass at $250 \mathrm{~g} \mathrm{~mol}^{-1}$.

\subsubsection{Indication of the potential influence of organic component non-ideality}

The main focus of the current work has been on the effect of water on absorptive partitioning of organic compounds resulting solely from water vapour being very many orders of magnitude more abundant than any other semi-volatile vapour. The impact on partitioning resulting from its low molecular weight via the first term in Eq. (6) has been shown to be dependent on model formulation and the relative magnitude of the impacts of the first and second terms will therefore be dependent on both non-ideality of the water/organic mixture and consistency of the formulation of the model and activity coefficients used. To gain some broad insight into the possible effects of non-ideality, the activity coefficients of each of the condensed organic components has been parameterised in the molar partitioning model such that each 


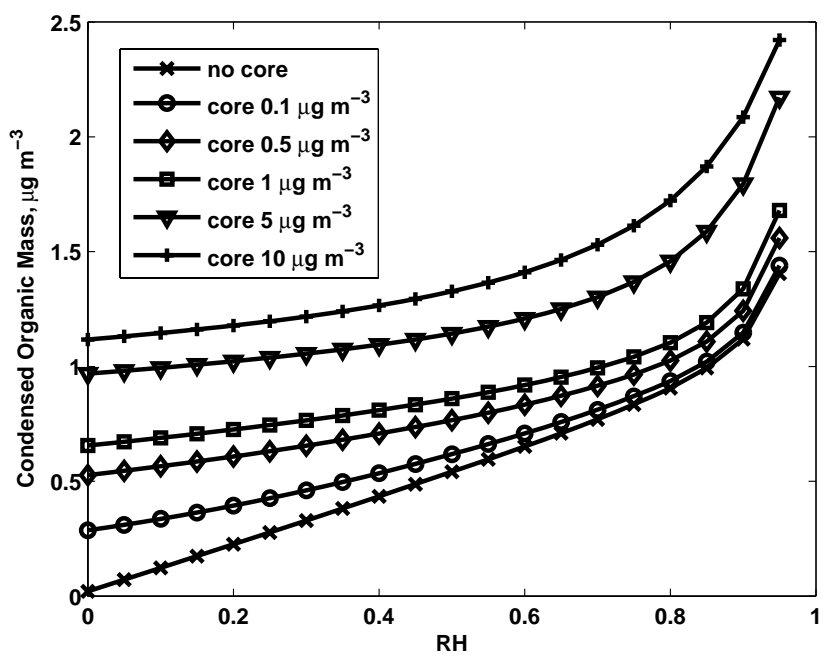

Fig. 8. Core mass dependence of condensed organic mass determined using the molar partitioning model.

may have a positive or negative deviation from ideality, leading to "salting out", $\left(\frac{\delta \ln \gamma_{i}}{\delta \mathrm{RH}}>0\right)$, or "salting in", $\left(\frac{\delta \ln \gamma_{i}}{\delta \mathrm{RH}}<0\right)$ respectively. The low abundance case study from Sect. 3.1 was used but with a fully-miscible but involatile organic core mass of $1 \mu \mathrm{g} \mathrm{m}^{-3}$, and a parameterisation of the activity coefficient of each component as a function of relative humidity (and hence water activity in solution). The parameterisation for negative and positive deviations took the forms $\left(1-0.9 a_{w}^{2}\right)$ and $\left(1+5 a_{w}\right)^{2}$ respectively. It is quite obvious that these forms of component activity are unrealistic simplifications of the real dependences, but the intention here is to explore the potential magnitude of the impact of non-ideality on partitioning, not the magnitude of partitioning for any real component. It can be seen from Fig. 9 that, in all cases examined, the dependence of the mass loading of the semi-volatile organic components on RH is still large.

As might be expected given the huge atmospheric abundance of water, in no case is condensed organic mass independent of RH. The shape of the dependence will obviously vary with the form of the activity coefficient expression, but organic component non-ideality will not generally lead to a small dependence on RH. It should be noted that the same degree of non-ideality in the different volatility components leads to a different mass loading and dependence of mass loading on RH. If the deviation from non-ideality is negative, the dependence on $\mathrm{RH}$ is greater if the more volatile component is non-ideal than if the less volatile component is non-ideal. Conversely, if the deviation from non-ideality is positive, the dependence on $\mathrm{RH}$ is greater if the less volatile component is non-ideal than if the more volatile component is non-ideal. Such a crude exploration of the effects of nonideality obviously does not account for effects such as phase separation or mixed solvent systems and assumes that the re-

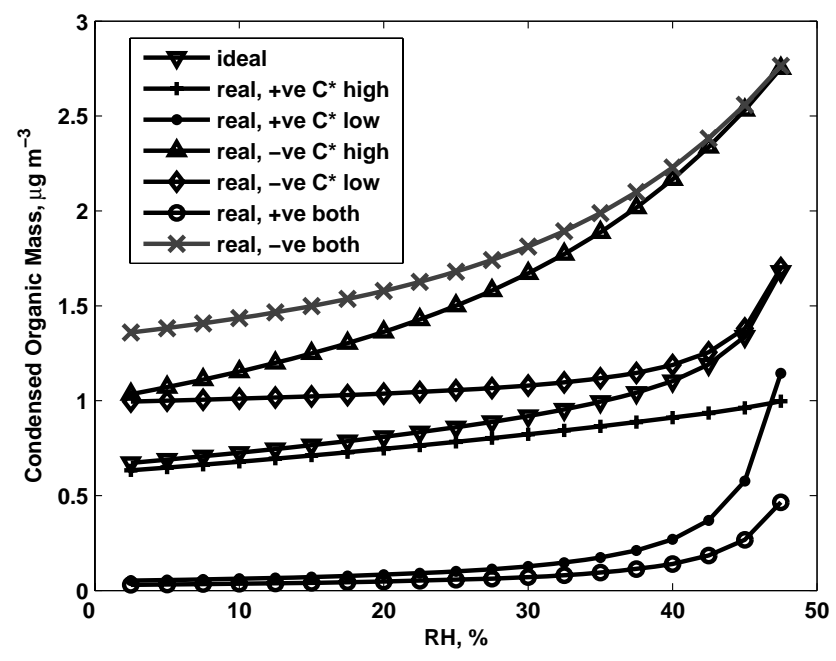

Fig. 9. Simplified representation of the effect of organic component non-ideality on the predicted condensed organic mass. Either or both of the two condensing organics were provided with hypothetical non-ideality parameterised as a function of RH with either positive or negative deviation from ideality (e.g. the effect of a negative deviation from ideality for the low volatility component is denoted "real, - ve $C^{*}$ low"). The non-ideality of water was not considered.

sultant condensed phase is miscible across its entire composition range. The molar-based model has been explicitly coupled to a multicomponent thermodynamic model and this is the subject of a more detailed study of these phenomena.

\subsection{Partitioning of simulated condensable OVOCs from the oxidation of atmospheric VOCs}

The MCM incorporated into a trajectory model framework has previously been used to simulate the chemical composition of anthropogenically polluted air arriving at Writtle in south-east England for the hour ending 18:00 on 06/08/2003 (Utembe et al., 2005; Johnson et al., 2006a,b), in conjunction with measurements made as part of the Tropospheric ORganic CHemistry (TORCH) project. In the present work, partitioning of some 3380 closed shell (nonradical and neutral) species at their simulated total abundances (in molecule $\mathrm{cm}^{-3}$ ) was estimated using the Mass_3, Mass 4 and Mol versions of the partitioning model, using the distribution of the predicted closed shell components simulated by (Johnson et al., 2006a,b). The molecular weights and vapour pressure values were calculated for all the closed shell species and the compounds were binned according to their calculated $C_{i}^{*}$ values. For each bin an abundance averaged $C_{i}^{*}$ and molecular weight were calculated. For a given compound the $C_{i}^{*}$ value used in the Mass_ 3 method is divided by the molecular weight to obtain the $C_{i}^{*}$ value used in the Mol method. 
The bins used in the two methods will therefore not contain the same compounds and for the less volatile compounds the bin number $\left(\log _{10}\left(C_{i}^{*}\right)\right)$ for the Mass 3 method will be on average 2 units higher than for the Mol method. Hence in Fig. 10, where the predicted SOA is shown as a distribution among the least volatile bins, the $\log _{10}\left(C_{i}^{*}\right)$ values shown are those for the Mass 3 method (rest; $-3 /-4,-2,-1$ etc.); while the corresponding bin designations for the Mol method are 2 units lower (rest; $-5 /-6,-4,-3$ etc...) and when comparing the distribution between the two methods a direct comparison between individual bins is not entirely meaningful as they will contain different components.

In the absence of water the two methods give similar amounts of SOA (Mass_3 $46.9 \mathrm{ng} \mathrm{m}^{-3}$, Mol $43.0 \mathrm{ng} \mathrm{m}^{-3}$ ). Bin 1 in the Mass 3 method (roughly corresponding to bin -1 in the Mol method) contains a higher abundance of species than the bins on either side. In the Mass_ 3 model in dry conditions this results in $4.03 \mathrm{ng} \mathrm{m}^{-3}$ of SOA from this bin alone (but $<1 \mathrm{ng} \mathrm{m}^{-3}$ from the -1 bin in the Mol model). At $80 \% \mathrm{RH}$, total SOA for the Mass 3 model increases to $91.8 \mathrm{ng} \mathrm{m}^{-3}$ (in addition to $367 \mathrm{ng} \mathrm{m}^{-3}$ of condensed water) while in the Mol model the total SOA is $53.4 \mathrm{ng} \mathrm{m}^{-3}$ (condensed water $=15.78 \mathrm{ng} \mathrm{m}^{-3}$. The distribution of SOA over the seven lowest volatility bins as predicted by these two models at $80 \%$ RH is shown in Fig. 10. Note that the major differences seen in the predictions in the two least volatile bins (labelled $-3 /-4$ and rest) are an artifact of the positioning of the bin boundaries. Both models predict that the vast majority of material in these bins will condense to form aerosol and if the predicted amounts for these two bins are added together the two models are in reasonable agreement (39.3 vs. $40.3 \mathrm{ng} \mathrm{m}^{-3}$ ). A much more significant difference occurs for bin 1 where the Mass_3 model predicts $39.06 \mathrm{ng} \mathrm{m}^{-3}$ compared to $4.81 \mathrm{ng} \mathrm{m}^{-3}$ for the Mol method. This is related to the very high levels of condensed water predicted by the Mass_3 model at $80 \%$ RH. When the results were recalculated using the Mass_ 3 model but with the $\mathrm{RH}$ reduced to $24.27 \%$ (so that the Mass_3 model predicted the same amount of condensed water as the Mol model at $80 \% \mathrm{RH})$, the SOA predicted by the Mass 3 model in bin 1 was reduced to $5.58 \mathrm{ng} \mathrm{m}^{-3}$, in much closer agreement with the Mol model $\left(4.81 \mathrm{ng} \mathrm{m}^{-3}\right)$ and demonstrating that the major factor in the high SOA content predicted by the Mass_3 model for bin 1 was the very high condensed water mass.

In summary, the two models predict a different distribution of SOA, with the Mass 3 model predicting a greater condensed organic abundance. The differences do not affect the least volatile organic components (which are predicted to condense to a high degree by both models) but rather the intermediate volatility compounds where only a small fraction condenses. For such components the increased mass of the total aerosol predicted by Mass_3 (because of the large contribution made by condensed water) can alter the degree of condensation by a factor of 10 or more resulting in significant differences from the Mol model as seen in Fig. 10. This

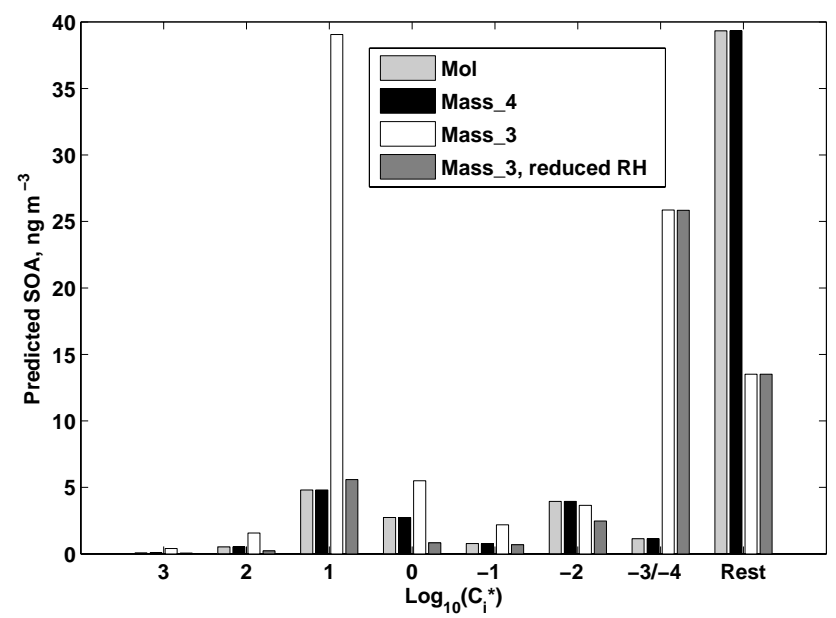

Fig. 10. Predicted SOA distribution by three models using molecular abundances from the MCM at $80 \% \mathrm{RH}$. Also shown is the same calculation using Mass_3 model with the RH reduced to $24.27 \%$, where Mass_3 predicts the same amount of condensed water as the other models, see text.

results entirely from the difference in molecular weights of the components (most notably from that of water, though not entirely). The Mass_4 and Mol models produce identical results and are simply re-expressions of the same Laws - the only advantage being that the Mol model does not require the calculation of an average molecular weight. Both expressions comply with Raoult's Law. The Mass_3 model contravenes Raoult's Law with the result that lower molecular weight components partition preferentially to the condensed phase in comparison with the Mass_4 and Mol models.

\section{Discussion and conclusions}

Water is a major component of the atmosphere and the most abundant potentially condensable component under ambient conditions. In attempting to model the condensation of atmospheric semi-volatiles into an aerosol it is important to account for the effects of water. In addition to its impacts on sub-saturated hygroscopic growth and cloud activation, water can potentially enhance SOA formation by acting as an absorptive medium. Irrespective of the difference in molecular mass of individual condensing components, a semi-volatile component as abundant in the atmosphere as water has the potential to influence the ambient loading of particulate material. At high total abundance of semi-volatile organic components, the presence of water may contribute a relatively minor amount of condensed material. However, the boundary layer abundance of water vapour will remain relatively constant at around 1 or $2 \%$ by volume. The condensable organics may vary much more appreciably and, as shown by Fig. 7, any particulate material formed at low total 
organic concentrations may strongly depend on the ambient $\mathrm{RH}$. It is predicted here that the RH dependence is much greater at low organic concentrations, comparable with those expected in the atmosphere. The dependence is much more marginal at concentrations more usually found in chamber experiments. It is therefore essential to establish whether water may have such an effect at or near atmospheric concentrations so that it can be established whether it is necessary to explicitly include it in the partitioning calculations.

The quantification of the dependence of organic component partitioning coefficient and hence condensed mass on water vapour concentration will depend on a range of factors, not least of which is whether absorptive partitioning should follow Raoult's Law. The supplemental material to Donahue et al. (2006) states that, for hydrocarbons of reasonably uniform density, it is more sensible to relate vapour pressure reduction to component mass, rather than mole, fraction. It is for this reason that, assuming ideality, the Mass $\_3$ model predicts much more water than the other two models and is the source of the discrepancy between the Mass_ 3 model and the flash calculation. For atmospheric purposes (and if the flash calculation is wrong, for distillation plant design and other chemical engineering applications), it is essential to establish whether Raoult's Law should be obeyed for the appropriate systems (or whether it is the most convenient base for correction by activity coefficients). In the atmosphere, that is for mixtures of multifunctional moderate molecular weight organic components and probably water.

The predicted mass of absorbed semi-volatile components is obviously dependent on the mass of pre-existing involatile but fully miscible material assumed to be present, but the RH dependence is predicted to be largely independent of the core mass. Obviously, introduction of a large core mass will make detection of a small amount of absorbed material more difficult, so experiments aiming to investigate the dependence of SOA loading on RH at low parent hydrocarbon concentrations should be carried out with at most a modest loading of absorptive core material.

It must be clearly noted and emphasised that the current study largely ignores the effects of non-ideality (though it is briefly addressed in Sect. 3.3.3 and by Fig. 9). Note that, in ideality since all component activity coefficients are assumed unity, the dependence is purely associated with the large number of condensing moles of water (equivalent to the first term in Eq. 6). Both laboratory and modelling studies of the second term in Eq. (6) associated with the component activity coefficients should be encouraged. It was shown in Fig. 9 that a very simplified parameterisation of component non-ideality still led to a significant dependence of condensed organic and total mass on RH. A more explicit inclusion of component activity coefficients in the Mol formulation of the model is the focus of a companion manuscript. Because of the huge potential range of organic components in ambient particles, it is expected that there will be a wide range of activity coefficients, and potentially a significant de- gree of phase separation. Whether such effects are zeroeth order needs to be the subject of extensive further study. It is possible that the activity coefficients of components are systematically underpredicted in the presence of other components, most notably water and the low aqueous solubility of even the most soluble organic components relative to inorganic electrolytes may lead to relatively high activity coefficients close to their solubility limit. Having said this, the extremely high abundance of water vapour in the lower atmosphere means that there is always water available for hydration of willing molecules.

It should also be noted that it is widely expected for organic component volatility to be reduced by substitution of oxygen containing functional groups, increasing their polarity. It is therefore more likely that the water activity coefficient is closer to unity at lower organic precursor concentrations and therefore that the relative humidity dependence is close to that depicted in Fig. 7). However, owing to the significant contribution of more volatile and probably less polar molecules to the aerosol mass at higher concentrations, the aerosol solution non-ideality will be greater and the water activity coefficient will be significantly greater than unity. This result may contribute to the apparent discrepancy between the chamber observations of low or negative dependence of aerosol yield on relative humidity and the positive dependence observed in flow tube experiments at lower concentrations (Jonsson et al., 2006). This result should be the focus of further laboratory investigation, since it has important consequences on the applicability of extrapolation of the results from high concentration experiments to atmospheric conditions.

Acknowledgements. This work was supported by the UK NERC "QUantifying the Earth SysTem" (QUEST) project under the "QUest Aerosol and Atmospheric Chemistry" (QUAAC) grant number NE/C001613/1 and by the EU funded "European Integrated project on Aerosol Cloud Climate and Air Quality interactions' (EUCAARI) under contract number 036833-2. D.O.T. is funded under a UK National Centre for Atmospheric Science (NCAS) Fellowship.

Edited by: J. Seinfeld

\section{References}

Ambrose, D. and Sprake, C. H. S.: Thermodynamic properties of organic oxygen compounds, 25, Vapour pressures of aliphatic alcohols, Journal of Chemical Thermodynamics, 2, 631-645, 1970.

Ambrose, D., Sprake, C. H. S., and Townsend, R.: Thermodynamic properties of organic oxygen compounds, 33, Vapor pressure of acetone, Journal of Chemical Thermodynamics, 6, 693-700, 1974.

Bloss, C., Wagner, V., Jenkin, M. E., Volkamer, R., Bloss, W. J., Lee, J. D., Heard, D. E., Wirtz, K., Martin-Reviejo, M., Rea, G., Wenger, J. C., and Pilling, M. J.: Development of a de- 
tailed chemical mechanism (MCMv3.1) for the atmospheric oxidation of aromatic hydrocarbons, Atmos. Chem. Phys., 5, 641664,2005 ,

http://www.atmos-chem-phys.net/5/641/2005/.

Cantrell, W., and Heymsfield, A.: Production of ice in tropospheric clouds - a review, B. Am. Meteorol. Soc., 86, 795-807, 2005.

Chang, E. I. and Pankow, J. F.: Organic particulate matter formation at varying relative humidity using surrogate secondary and primary organic compounds with activity corrections in the condensed phase obtained using a method based on the Wilson equation, Atmos. Chem. Phys. Discuss., 8, 995-1039, 2008, http://www.atmos-chem-phys-discuss.net/8/995/2008/.

Donahue, N. M., Robinson, A. L., Stanier, C. O., and Pandis, S. N.: Coupled partitioning, dilution, and chemical aging of semivolatile organics, Environ. Sci. Technol., 40, 2635-2643, 2006.

Erdakos, G. B., and Pankow, J. F.: Gas/particle partitioning of neutral and ionizing compounds to single- and multi-phase aerosol particles. 2. Phase separation in liquid particulate matter containing both polar and low-polarity organic compounds, Atmos. Environ., 38, 1005-1013,2004.

Erdakos, G. B., Asher, W. E., Seinfeld, J. H., and Pankow, J. F.: Prediction of activity coefficients in liquid aerosol particles containing organic compounds, dissolved inorganic salts, and waterPart 1: Organic compounds and water by consideration of shortand long-range effects using X-UNIFAC.1, Atmos. Environ., 40, 6410-6421,2006.

Finlayson-Pitts, B. J. and Pitts, J. N.: Chemistry of the upper and lower atmosphere: Theory, experiments and applications, Academic Press, 1999.

Florusse, L. J., Fornari, T., Bottini, S. B., and Peters, C. J.: Phase behavior of the binary system near-critical dimethylether and tripalmitin: Measurements and thermodynamic modeling, Journal of Supercritical Fluids, 22, 1-13, 2002.

Gray, H. A., Cass, G. R., Huntzicker, J. J., Heyerdahl, E. K., and Rau, J. A.: Characteristics of atmospheric organic and elemental carbon particle concentrations in los angeles., Environ. Sci. Technol., 20, 580-582, 1986.

Jenkin M. E., Saunders S. M., and Pilling M. J.: The tropospheric degradation of volatile organic compounds: a protocol for mechanism development. Atmospheric Environment, 31, 81104, 1997.

Jenkin, M. E., Saunders, S. M., Wagner, V., and Pilling, M. J.: Protocol for the development of the Master Chemical Mechanism, MCM v3 (Part B): tropospheric degradation of aromatic volatile organic compounds, Atmos. Chem. Phys., 3, 181-193, 2003, http://www.atmos-chem-phys.net/3/181/2003/.

Johnson, D., Jenkin, M. E., Wirtz, K., and Martin-Reviejo, M.: Simulating the formation of secondary organic aerosol from the photooxidation of aromatic hydrocarbons, Environmental Chemistry, 2, 35-48, 2005.

Johnson, D., Utembe, S. R., Jenkin, M. E., Derwent, R. G., Hayman, G. D., Alfarra, M. R., Coe, H., and McFiggans, G.: Simulating regional scale secondary organic aerosol formation during the TORCH 2003 campaign in the southern UK, Atmos. Chem. Phys., 6, 403-418, 2006a, http://www.atmos-chem-phys.net/6/403/2006/.

Johnson, D., Utembe, S. R., and Jenkin, M. E.: Simulating the detailed chemical composition of secondary organic aerosol formed on a regional scale during the TORCH 2003 campaign in the southern UK, Atmos. Chem. Phys., 6, 419-431, 2006b,

http://www.atmos-chem-phys.net/6/419/2006/.

Jonsson, A. M., Hallquist, M., and Ljungstrom, E.: Impact of humidity on the ozone initiated oxidation of limonene, $\Delta$ (3)carene, and $\alpha$-pinene, Environmental Science and Technology, 40, 188-194, 2006.

Kamens, R., Jang, M., Chien, C. J., and Leach, K.: Aerosol formation from the reaction of alpha-pinene and ozone using a gasphase kinetics aerosol partitioning model, Environ. Sci. Technol., 33, 1430-1438, 1999.

Kanakidou, M., Seinfeld, J. H., Pandis, S. N., Barnes, I., Dentener, F. J., Facchini, M. C., Van Dingenen, R., Ervens, B., Nenes, A., Nielsen, C. J., Swietlicki, E., Putaud, J. P., Balkanski, Y., Fuzzi, S., Horth, J., Moortgat, G. K., Winterhalter, R., Myhre, C. E. L., Tsigaridis, K., Vignati, E., Stephanou, E. G., and Wilson, J.: Organic aerosol and global climate modelling: a review, Atmos. Chem. Phys., 5, 1053-1123, 2005,

http://www.atmos-chem-phys.net/5/1053/2005/.

McFiggans, G., Artaxo, P., Baltensperger, U., Coe, H., Facchini, M. C., Feingold, G., Fuzzi, S., Gysel, M., Laaksonen, A., Lohmann, U., Mentel, T. F., Murphy, D. M., O’Dowd, C. D., Snider, J. R., and Weingartner, E.: The effect of physical and chemical aerosol properties on warm cloud droplet activation, Atmos. Chem. Phys., 6, 2593-2649, 2006,

http://www.atmos-chem-phys.net/6/2593/2006/.

Middlebrook, A. M., Murphy, D. M., and Thomson, D. S.: Observations of organic material in individual marine particles at cape grim during the first aerosol characterization experiment (ACE 1), J. Geophys. Res.-Atmos., 103, 16475-16483, 1998.

Nannoolal, Y., Rarey, J., Ramjugernath, D., and Cordes, W.: Estimation of pure component properties part 1. Estimation of the normal boiling point of non-electrolyte organic compounds via group contributions and group interactions, Fluid Phase Equilibria, 226, 45-63, 2004.

Nannoolal, Y., Rarey, J., and Ramjugernath, D.: Estimation of pure component properties. Part 3. Estimation of the vapor pressure of non-electrolyte organic compounds via group contributions and group interactions, Fluid Phase Equilibria, 269, 117-133, 2008.

Odum, J. R., Hoffmann, T., Bowman, F., Collins, D., Flagan, R. C., and Seinfeld, J. H.: Gas/particle partitioning and secondary organic aerosol yields, Environ. Sci. Technol., 30, 2580-2585, 1996.

Odum, J. R., Jungkamp, T. P. W., Griffin, R. J., Flagan, R. C., and Seinfeld, J. H.: The atmospheric aerosol-forming potential of whole gasoline vapor, Science, 276, 96-99, 1997.

Pankow, J. F.: Review and comparative-analysis of the theories on partitioning between the gas and aerosol particulate phases in the atmosphere, Atmos. Environ., 21, 2275-2283, 1987.

Pankow, J. F.: An absorption-model of gas-particle partitioning of organic-compounds in the atmosphere, Atmos. Environ., 28, 185-188, 1994.

Pankow, J. F., Seinfeld, J. H., Asher, W. E., and Erdakos, G. B.: Modeling the formation of secondary organic aerosol. 1. Application of theoretical principles to measurements obtained in the $\alpha$-pinene, $\beta$ - pinene, sabinene, $\Delta(3)$-carene, and cyclohexene/ozone systems, Environ. Sci. Technol., 35, 1164-1172, 2001.

Pankow, J. F and Chang, E. I.: Variation in the sensitivity of pre- 
dicted levels of atmospheric organic particulate matter (OPM), Environ. Sci. Technol., 42, 7321-7329, 2008.

Raal, J. D., and Muhlbauer, A. L.: Phase equilibria, measurement and computation, Series in chemical and mechanical engineering, edited by: Hewitt, G. F., and Tien, C. L., Taylor and Francis, Washington, D C., 1998.

Salerno, S., Cascella, M., May, D., Watson, P., and Tassios, D.: Prediction of vapor-pressures and saturated volumes with a simple cubic equation of state .1. A reliable database, Fluid Phase Equilibria, 27, 15-34, 1986.

Saunders, S. M., Jenkin, M. E., Derwent, R. G., and Pilling, M. J.: Protocol for the development of the Master Chemical Mechanism, MCM v3 (Part A): tropospheric degradation of nonaromatic volatile organic compounds, Atmos. Chem. Phys., 3, 161-180, 2003, http://www.atmos-chem-phys.net/3/161/2003/.

Saxena, P., and Hildemann, L. M.: Water absorption by organics: Survey of laboratory evidence and evaluation of unifac for estimating water activity, Environ. Sci. Technol., 31, 3318-3324, 1997.

Schmidt, E., and Grigull, V.: Properties of water and steam in SIunits; table 1, 22 p., Third ed., Springer-Verlag, Berlin, 1982.

Seinfeld, J. H. and Pandis, S. N.: Atmospheric chemistry and physics: From air pollution to climate change, WileyInterscience publications, 1998.

Seinfeld, J. H., and Pankow, J. F.: Organic atmospheric particulate material, Annual Review of Physical Chemistry, 54, 121-140, 2003.
Seinfeld, J. H., Asher, W. E., Erdakos, G. B., and Pankow, J. F.: Modeling the formation of secondary organic aerosol (SOA). 2. The predicted effects of relative humidity on aerosol formation in the $\alpha$-pinene-, $\beta$-pinene-, sabinene-, $\Delta^{3}$-Carene-, and cyclohexene-ozone systems, Environ. Sci. Technol., 35, 18061817, 2001.

Soderholm, S. C.: Aerosol instabilities, Applied Industrial Hygene, 3, 35-38, 1988.

Solomon, S., D. Qin, M. Manning, Z. Chen, M. Marquis, K. B. Averyt, M. Tignor, and H. L. Miller.: IPCC, Climate Change 2007: The Physical Science Basis. Contribution of Working Group I to the Fourth Assessment Report of the Intergovernmental Panel on Climate Change, Cambridge University Press, Cambridge, United Kingdom and New York, NY, USA, 996 pp., 2007

Swietlicki, E., Hansson, H. C., Hameri, K., Svenningsson, B., Massling, A., McFiggans, G., McMurry, P. H., Petaja, T., Tunved, P., Gysel, M., Topping, D., Weingartner, E., Baltensperger, U., Rissler, J., Wiedensohler, A., and Kulmala, M.: Hygroscopic properties of submicrometer atmospheric aerosol particles measured with h-tdma instruments in various environments - a review, Tellus Series B-Chemical and Physical Meteorology, 60, 432-469, 2008.

Utembe S. R., Jenkin M. E., Derwent R. G., Lewis A. C., Hopkins J. R., and Hamilton J. F.: Modelling the ambient distribution of organic compounds during the August 2003 ozone episode in the southern UK, Faraday Discussions, 130, 311-326, 2005.

Zhang, Q., Worsnop, D. R., Canagaratna, M. R., and Jimenez, J. L.: Hydrocarbon-like and oxygenated organic aerosols in Pittsburgh: insights into sources and processes of organic aerosols, Atmos. Chem. Phys., 5, 3289-3311, 2005, http://www.atmos-chem-phys.net/5/3289/2005/. 